\title{
Quantification of Bioactive Compounds and Evaluation of the Antioxidant Activity of Carissa edulis Valh (Apocynaceae) Leaves
}

\author{
Sabine Adeline Fanta Yadang $\mathbb{D}^{1,2}$ Germain Taiwe Sotoing $\mathbb{D}^{1}{ }^{3}$ \\ Katoucha Sidoine Ngatcha Zouakeu $\left(\mathbb{D},{ }^{2}\right.$ Muhammad Ahsan Khan $\left(\mathbb{D},{ }^{4}\right.$ \\ Gabriel Agbor Agbor $\left(\mathbb{D},{ }^{1}\right.$ Nisar Ur-Rahman, ${ }^{4}$ and Elisabeth Ngo Bum ${ }^{2,5}$ \\ ${ }^{1}$ Institute of Medical Research and Medicinal Plants Studies, Ministry of Scientific Research and Innovation, Yaoundé, Cameroon \\ ${ }^{2}$ Department of Biological Sciences, Faculty of Science, University of Ngaoundere, Cameroon \\ ${ }^{3}$ Department of Zoology and Animal Physiology, Faculty of Science, University of Buea, Cameroon \\ ${ }^{4}$ Department of Pharmacy, Comsats University Islamabad, Abbottabad Campus, Pakistan \\ ${ }^{5}$ Institute of Mining and Petroleum Industries, University of Maroua, Cameroon
}

Correspondence should be addressed to Sabine Adeline Fanta Yadang; fantayadang@gmail.com

Received 14 February 2019; Accepted 28 April 2019; Published 15 May 2019

Academic Editor: Paula B. Andrade

Copyright (c) 2019 Sabine Adeline Fanta Yadang et al. This is an open access article distributed under the Creative Commons Attribution License, which permits unrestricted use, distribution, and reproduction in any medium, provided the original work is properly cited.

\begin{abstract}
Carissa edulis is a plant used in the management of oxidative stress and inflammatory related disorders such as malaria, rheumatism inflammation, and cardiovascular diseases. The present study evaluates the total phenolic content, antioxidant capacity (DPPH, ABTS, and FRAP), and the bioactive compounds present in the various extracts of C. edulis (HEC, MEC, AEC, and PC). An HPLC analysis determined the different compounds present in the extracts. High concentration of total phenolic content was observed in aqueous and methanolic extracts more than in the hydroethanolic extract though not significantly different. Flavonoids were higher in the hydroethanolic and methanolic extracts, respectively, with $14.84 \mathrm{mg}$ RE/g extract and $12.02 \mathrm{mg}$ RE/g extract. Tannins were also found in large amounts in the same two extracts with $26.76 \mathrm{mg}$ TAE/g extract and $34.67 \mathrm{mg}$ TEE/g extract. The percentage radical scavenging activity DPPH ranged between $58.63 \%$ and $94.67 \%$ for aqueous extract and for ABTS between $51.39 \%$ and $94.12 \%$ for the methanolic extract. The highest FRAP was obtained in the methanolic extract ( $6.73 \mathrm{~g}$ AAE/100 g extract). HPLC analysis revealed the presence of quercetin, rutin, and gallic acid in the different extracts. C. edulis represents a potential source of bioactive components with antioxidant capacity.
\end{abstract}

\section{Introduction}

Mitochondrial oxidative phosphorylation, which is a process that leads to energy production, is a phenomenon that occurs in most aerobic organisms. The partial electron transfer of oxygen molecules during this metabolism leads to the production of unstable molecules such as the superoxide anion $\mathrm{O}^{2-}$ which is the radical form among reactive oxygen species (ROS). The ROS includes free radicals such as $\mathrm{O}^{2-}$, hydroxyl radical $\mathrm{HO}^{-}$, and also hydrogen peroxide $\mathrm{H}_{2} \mathrm{O}_{2}$ which is a nonradical species but is capable of liberating hydroxyl radicals according to the Fenton reaction. The increased level of these free radicals causes oxidative stress. These ROS play an important role in the physiological and pathological process. Under normal conditions, the level of free radicals is controlled by an antioxidant defense system that decreases oxidative damage [1]. Oxidative stress is considered a major contributor to many chronic diseases [2]. Therefore, an antioxidant intake is needed to reduce the excess of the ROS and thus suppress oxidative damage. An antioxidant is a substance that even at low concentration delays and prevents the oxidation of the substrate [3]. Plants 
are an important source of natural antioxidants and their compounds have been reported to reduce oxidative stress by acting as an antioxidant [4].

Carissa edulis is a plant of the Apocynaceae family which consists of more than 250 genera and 2000 species [5]. It is widely distributed in Africa and in Cameroon; it is found in the Sudano-Sahel savannahs. The plant Carissa edulis is reputed in traditional medicine as a good source of medicine for the treatment of rheumatism [6], headaches, epilepsy, gonorrhoea, syphilis, and rabies and is often used as a diuretic $[7,8]$. It has also been reported to treat fever, hernia, sickle cell anaemia, ulcer, worm infestation, pain, and inflammation $[9,10]$. Several classes of chemical constituents have been isolated, such as sesquiterpenes, cardiac glycosides, phenolic compounds, flavonoids, lignans, sterols, tannins, proanthocyanidins, chlorogenic acid derivatives $[5,11,12]$, and 2hydroxacetophenone [13]. In addition, there are six volatile compounds of $C$. edulis root that have been analysed by GC/MS [14]. C. edulis has also shown pharmacological activities such as antimicrobial [15], diuretic [7], hypoglycaemic [16], anticonvulsant [17], antiviral [18], anti-inflammatory [19], and antiplasmodial [20, 21].

In this study, the leaf extracts of $C$. edulis were analysed using HPLC; the quantification of total phenolic, flavonoids, and tannins content and the antioxidant capacity as measured by DPPH, ABTS, and FRAP method were evaluated.

\section{Material and Method}

2.1. Plant Material. Fresh leaves of Carissa edulis were collected in Bogo, in the Diamare subdivision of the Far Northern Region of Cameroon in the month of June 2016. The botanical identification was done at the National Herbarium of Yaoundé (Cameroon) where voucher specimen was kept under the number 2965/SRFK. The leaves of C. edulis collected were washed, dried in the shade, crushed, and then sieved to obtain a fine powder.

2.2. Preparation of Extracts. Five hundred grams (500g) of powder were macerated, respectively, with $3 \mathrm{~L}$ of ethanol (70\% ethanol-30\% water), methanol, and water for 2 days. The macerate obtained was filtered and evaporated using a rotary evaporator (BUCHI Rotavapor R-300) at $50^{\circ} \mathrm{C}$. After that it was dried in an oven (Heratherm oven). The extracts obtained either hydroethanolic (HEC), methanolic (MEC), or aqueous (AEC) were preserved and used for the determination of compounds and antioxidant activity.

2.3. Drugs and Chemicals. Chemicals include Folin-Ciocalteu, sodium carbonate, gallic acid, aluminium chloride, sodium acetate, rutin, vanillin, tannic acid, 2,2-diphenyl-1picrylhydrazyl (DPPH), ABTS (2,2' -azinobis-(3-éthylbenzothiazoline-6-sulfonique)), potassium ferricyanide, trichloroacetic acid, iron III chloride, ascorbic acid, potassium persulfate, quercetin, acetonitrile (Biochem, Chemopharma), ethanol, methanol, acetone, acetic acid, hydrochloric acid. All chemicals were purchased from Sigma Aldrich St Louis, USA, Daejung, Korea, and local suppliers.
2.4. HPLC Analysis. HPLC analysis used for determination of different compounds present in our extracts was performed on a SCHIMADZU LC-20AP system equipped with a binary solvent dispensing pump, an autosampler, and an SPD20AV UV/visible detector and controlled by the EmpowerII software. A reversed-phase RP-U8 OB column (150 mm x $4.6 \mathrm{~mm}$ ID, particle size $5 \mu \mathrm{m}$ ) was used for all separations at a column temperature of $30^{\circ} \mathrm{C}$. The mobile phase composed of $\mathrm{A}$ ( $1 \%$ acetic acid in acetonitrile) and $\mathrm{B}$ ( $1 \%$ acetic acid in water) with gradient elution $0 \mathrm{~min}(5 \% \mathrm{~A}), 0-21 \mathrm{~min}(5-$ $20 \%$ A), $21-30$ min (20-25\% A), 30-32 min (25-100\% A), 32$39 \mathrm{~min}(100-100 \% \mathrm{~A}), 39-40 \mathrm{~min}(100-5 \% \mathrm{~A})$, and $40-45 \mathrm{~min}$ (5-5\% A) was used in this study. The injection volume of the sample was $1 \mu \mathrm{l}$, and the flow rate was set at $0.6 \mathrm{ml} / \mathrm{min}$. Standards and different extracts were prepared at $1 \mathrm{mg} / \mathrm{ml}$ and $5 \mathrm{mg} / \mathrm{ml}$ in HPLC grade methanol, respectively. Peaks were determined at $270 \mathrm{~nm}$. Characterization of the peaks was made according to their amplitude. Identification was performed using retention times and available standards. Quantification of the identified compounds was based on the percentage $\%$ peak area.

2.5. Total Phenolic Content. Total phenolic content was evaluated according to the spectrophotometric method using the Folin-Ciocalteu reagent described by Gao [22] with slight modifications. $0.3 \mathrm{~g}$ of different extracts was introduced into a test tube and a volume of $15 \mathrm{ml}$ of $70 \%$ ethanol (v/v) was added. The mixture was centrifuged at $3500 \mathrm{rpm}$ for 20 minutes and the supernatants were collected. About $0.02 \mathrm{ml}$ of supernatant was put into a test tube; then $1.38 \mathrm{ml}$ of distilled water and $0.2 \mathrm{ml}$ of Folin-Ciocalteu reagent were added. After standing for 3 minutes, $0.4 \mathrm{ml}$ of sodium carbonate $(7.5 \%$ $\mathrm{Na}_{2} \mathrm{CO}_{3}$ ) was added to the mixture. The tubes were vortexed and incubated for 20 minutes in a $40^{\circ} \mathrm{C}$ water bath and the absorbance was read against a blank at $760 \mathrm{~nm}$. Calibration was performed using a freshly prepared aqueous solution of gallic acid $(0.2 \mathrm{~g} / \mathrm{l})$. The results were expressed in milligrams equivalent of gallic acid per gram of dry extract.

2.6. Total Flavonoid Content. The flavonoids content in the extracts was determined by the method described by MimicaDukic [23]. For analysis, $0.25 \mathrm{~g}$ of powder of each extract was homogenized with $10 \mathrm{ml}$ of methanol-distilled water-acetic acid extraction solvent (140: 50: $10 \mathrm{v} / \mathrm{v}$ ). The homogenized mixture was filtered using Whatman No. 1 filter paper. To $0.2 \mathrm{ml}$ of extract solution, $1.8 \mathrm{ml}$ of distilled water and $1 \mathrm{ml}$ of the aluminium chloride reagent $\left(\mathrm{AlCl}_{3}\right)$ (consisting of $133 \mathrm{mg}$ of aluminium chloride crystals and $400 \mathrm{mg}$ of sodium acetate dissolved in $100 \mathrm{ml}$ of the extraction solvent) were added and the whole was vortex mixed and the absorbance was read against a blank at $430 \mathrm{~nm}$. The amount of flavonoids was calculated using a standard solution of rutin $(0.1 \mathrm{mg} / \mathrm{ml})$ and the results were expressed in milligrams of rutin per gram of dry extract.

2.7. Tannin Content. Tannin was determined using the spectrophotometric method using acidified vanillin [24]. About $1 \mathrm{~g}$ of the various extracts was introduced into an Erlenmeyer flask and $15 \mathrm{ml}$ of acetone (10\% acetic acid) was added. The 
mixture was stirred for 15 minutes and then filtered and diluted 20 times with distilled water before the assay. $1 \mathrm{ml}$ of the diluted mixture was added to each test tube coated with aluminium foil to exclude light followed by $3 \mathrm{ml}$ of a freshly prepared solution of $4 \%$ vanillin in ethanol $(\mathrm{w} / \mathrm{v})$. After stirring, $1 \mathrm{ml}$ of concentrated $\mathrm{HCl}$ was added to each tube which was then allowed to stand at room temperature for 15 minutes and the absorbance was read at $500 \mathrm{~nm}$ against a blank. The amount of tannins was calculated using a standard solution of tannic acid $(5 \mathrm{mg} / \mathrm{ml})$ and the results were expressed in milligrams of tannic acid per gram of solids.

\subsection{Antioxidant Activity}

2.8.1. DPPH Free Radical Scavenging Test. The antioxidant power which is the ability of a given substance to trap a free radical has been determined by the method of Zhang and Hamauzu [25] with some modifications. In a test tube containing $0.5 \mathrm{ml}$ of different concentration $(0.1-1 \mathrm{mg} / \mathrm{ml})$ of extract, $2 \mathrm{ml}$ of DPPH $(0.1 \mathrm{mM}$ prepared in methanol) was introduced. Then the mixture was stirred for $5 \mathrm{~min}$ and incubated in the dark for 60 minutes at room temperature. For the control tube, the methanol was used in place of the extract. The reference used was ascorbic acid at different concentrations. Tests were repeated three times at each concentration level. Absorbance was read at $517 \mathrm{~nm}$. The antioxidant activity was expressed as percent inhibition.

$$
\mathrm{I} \%=\left[\frac{(\text { Abs control }- \text { Abs sample })}{\text { Abs control }}\right] \times 100
$$

IC50 values were determined graphically by the linear regression line.

2.8.2. Inhibition of the Radical $A B T S^{+}$. It is one of the most widely used methods for determining the antioxidant activity of plant extracts; it consists in following the kinetics of discoloration of the $\mathrm{ABTS}^{+}$ion as described by Re et al. [26]. ABTS (2,2'-azinobis-(3-ethylbenzothiazolin-6-sulfonic acid)) was prepared by mixing $0.0384 \mathrm{~g}$ of ABTS and $0.00662 \mathrm{~g}$ of potassium persulfate $\left(\mathrm{K}_{2} \mathrm{~S}_{2} \mathrm{O}_{8}\right)$ with $10 \mathrm{ml}$ of distilled water. The mixture was incubated for $16 \mathrm{~h}$ at room temperature, protected from light before use. For the actual analysis, the ABTS solution was diluted with ethanol and the absorbance adjusted to $0.700( \pm 0.02)$ at $734 \mathrm{~nm}$ and was stable at $30^{\circ} \mathrm{C}$ (initial OD). In a test tube, $3.0 \mathrm{ml}$ of this diluted ABTS solution and $30 \mu \mathrm{l}$ of the extract of varying concentration $(0.25 \mathrm{mg} / \mathrm{ml}, 0.1 \mathrm{mg} / \mathrm{ml}, 0.05 \mathrm{mg} / \mathrm{ml}$, and $0.025 \mathrm{mg} / \mathrm{ml})$ were introduced and agitated to mix. Absorbance reading was taken at $734 \mathrm{~nm}$ immediately after agitation. Ascorbic acid was used as an antioxidant reference at the same concentrations as the extracts. The percent inhibition was calculated according to the formula:

$$
\mathrm{I} \%=\left[\frac{(\text { Abs control }- \text { Abs sample })}{\text { Abs control }}\right] \times 100
$$

2.8.3. Ferric Reducing Antioxidant Power (FRAP). The reducing power of iron $\left(\mathrm{Fe}^{3+}\right)$ in the extracts was determined according to the method described by Oyaizu [27]. $1 \mathrm{ml}$ of the extract was mixed with $2.5 \mathrm{ml}$ of $0.2 \mathrm{M}$ phosphate buffer solution $(\mathrm{pH} 6.6)$ and $2.5 \mathrm{ml}$ of $1 \%$ potassium ferricyanide $\left(\mathrm{K}_{3} \mathrm{Fe}(\mathrm{CN})_{6}\right)$ solution. This was then incubated in a water bath at $50^{\circ} \mathrm{C}$ for $20 \mathrm{~min}$. Then, $2.5 \mathrm{ml}$ of $10 \%$ trichloroacetic acid was added to stop the reaction and the tubes were centrifuged at $3000 \mathrm{rpm}$ for $10 \mathrm{~min}$. To $2.5 \mathrm{ml}$ of supernatant were added $2.5 \mathrm{ml}$ of distilled water and $0.5 \mathrm{ml}$ of an aqueous solution of iron chloride III $\left(0.1 \% \mathrm{FeCl}_{3}\right)$. The absorbance of the reaction mixture was read at $700 \mathrm{~nm}$ against a similarly prepared blank, by replacing the extract with distilled water which made it possible to calibrate the apparatus (UV-VIS spectrophotometer). The positive control was represented by a solution of a standard antioxidant, ascorbic acid whose absorbance was measured under the same conditions as the samples. An increase in absorbance corresponds to an increase in the reducing power of the extracts tested and the results were expressed in grams of ascorbic acid equivalent/100 $\mathrm{g}$ of dry extract.

2.9. Statistical Analysis. Each set of data was expressed as mean \pm ESM $(n=3)$. The analysis was done by ANOVA followed by Fisher's test and Dunnett's multiple comparison test. The difference between concentrations and extracts was considered significant at $\mathrm{p}<0.05$. The graphical representation of the data and the determination of the $\mathrm{IC}_{50}$ were performed using the Graph Pad Prism 5.0 software (Microsoft, USA).

\section{Results}

3.1. HPLC Analysis. Figure 1(b) shows the HPLC chromatogram of the methanolic extract where 22 peaks are distinguished. Figure 1(c) shows the chromatogram of the hydroethanolic extract with 9 peaks and Figure 1(d) shows the aqueous extract with 23 peaks. A total of 13 peaks were identified in the chromatogram of the $C$. edulis powder (Figure 1(e)). To find the phenolic compounds present in our extracts, the retention times of each peak of our extracts were compared to that of the standards (Figure 1(a)). The results show that the retention times of gallic acid, rutin, and quercetin are, respectively, RT5.33, RT22.50, and RT29.78 with composition percentages of $37.10 \%, 27.50 \%$, and $21.64 \%$.

3.2. Extraction Yield. The percent yield of extraction is shown in Table 1. The highest percentage was obtained when the leaves were extracted with methanol. The yield of the methanolic extract is significantly higher with $56.83 \%$ compared to the hydroethanolic and aqueous extracts which, respectively, have $36.64 \%$ and $23.14 \%$.

3.3. Total Phenolic Content. The phenolic content of each extract was expressed in milligrams of gallic acid per gram of dry matter and obtained from the calibration curve of gallic acid (Figure 2). The results presented in Table 1 show that the extracts have a significantly high content of polyphenol per gram of dry extract.

3.4. Flavonoid Content. The flavonoid content expressed in mg of rutin per $g$ of dry extract was obtained from the 
$\mathrm{mV}$

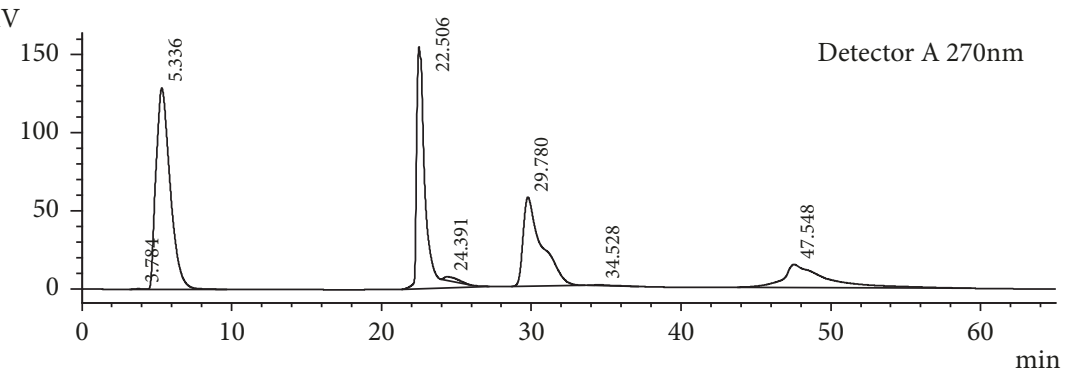

(a) HPLC chromatogram of mixture of standard gallic acid rutin and quercetin. (i) Gallic acid RT5.33. (ii) Rutin RT22.50. And (iii) Quercetin RT29.78 $\mathrm{mV}$

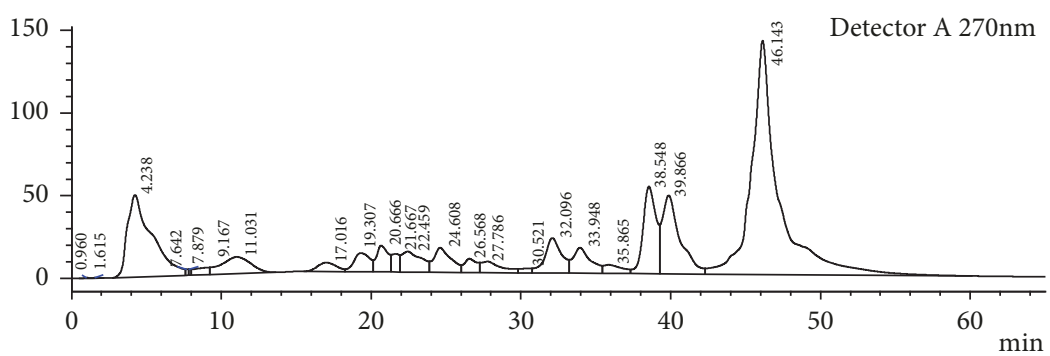

(b) HPLC chromatogram of the methanolic extract of C. edulis leaves

$\mathrm{uV}$

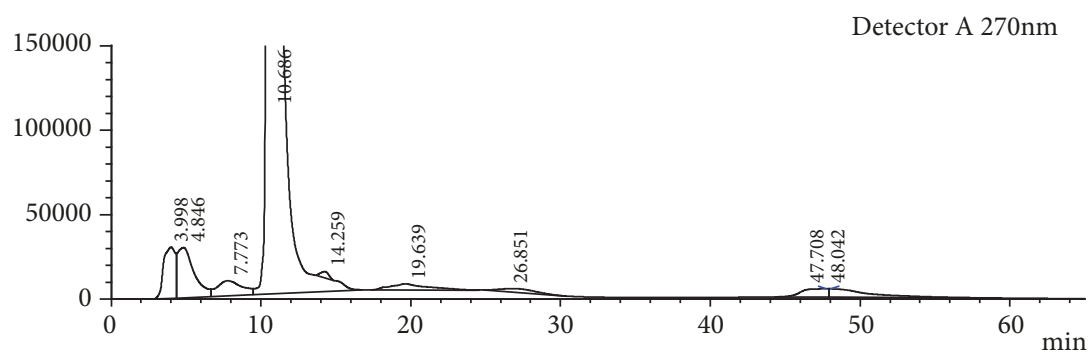

(c) HPLC chromatogram of the hydroethanolic extract of C. edulis leaves

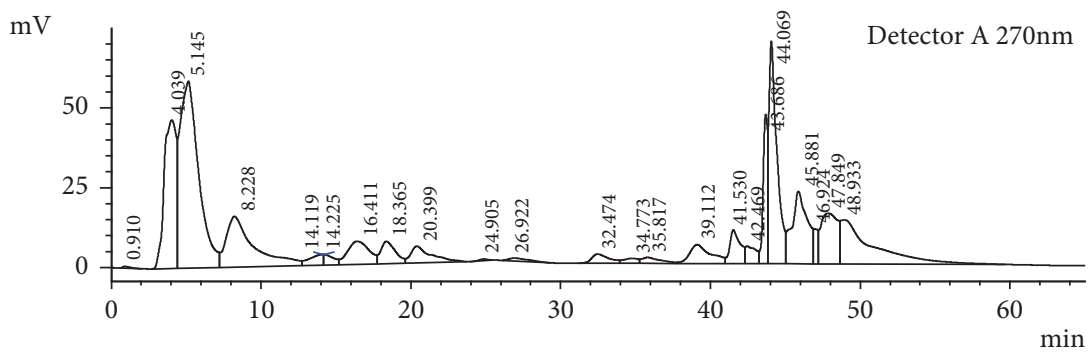

(d) HPLC chromatogram of the aqueous extract of C. edulis leaves

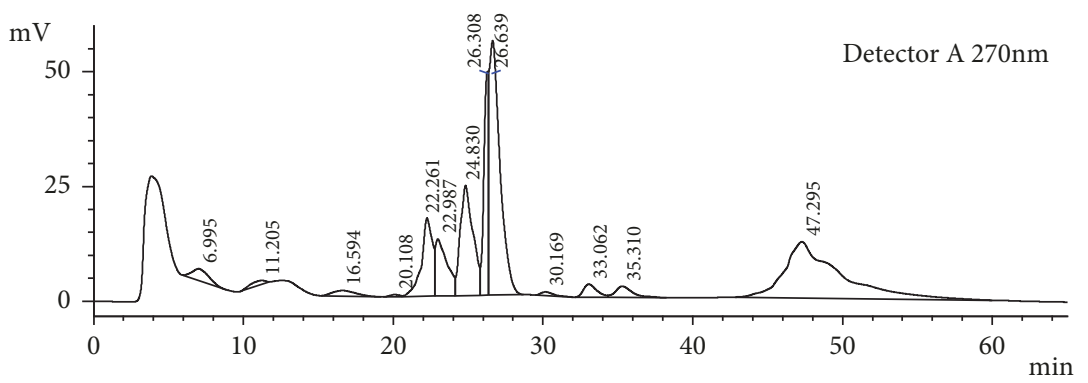

(e) HPLC chromatogram of the powder of C. edulis leaves

Figure 1 
Table 1: Percent yield, content of total polyphenols, flavonoids, and tannins contained in C. edulis.

\begin{tabular}{lcccc}
\hline Extracts & \% Yield & Total phenolic content $(\mathrm{mg} \mathrm{GAE} / \mathrm{g}$ extract) & Total flavonoid (mg Rutin/g extract) & Tannin (mg TAE/g extract) \\
\hline Hydroethanolic & 36.64 & $139.27 \pm 0.014$ & $14.84 \pm 0.013$ & $26.76 \pm 0.048$ \\
Methanolic & 56.83 & $146.82 \pm 0.001$ & $12.02 \pm 0.017$ & $34.67 \pm 0.042$ \\
Aqueous & 23.14 & $147.05 \pm 0.014$ & $5.88 \pm 0.120$ & $16.09 \pm 0.043$ \\
Powder & & $144.42 \pm 0.009$ & $5.24 \pm 0.017$ & $22.41 \pm 0.013$ \\
\hline
\end{tabular}

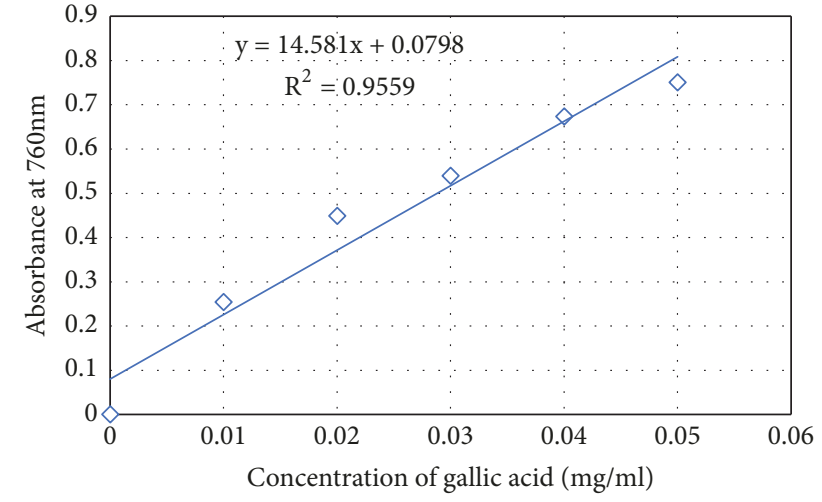

FIGURE 2: Calibration curve of gallic acid in determination of total phenolic content of C. edulis.

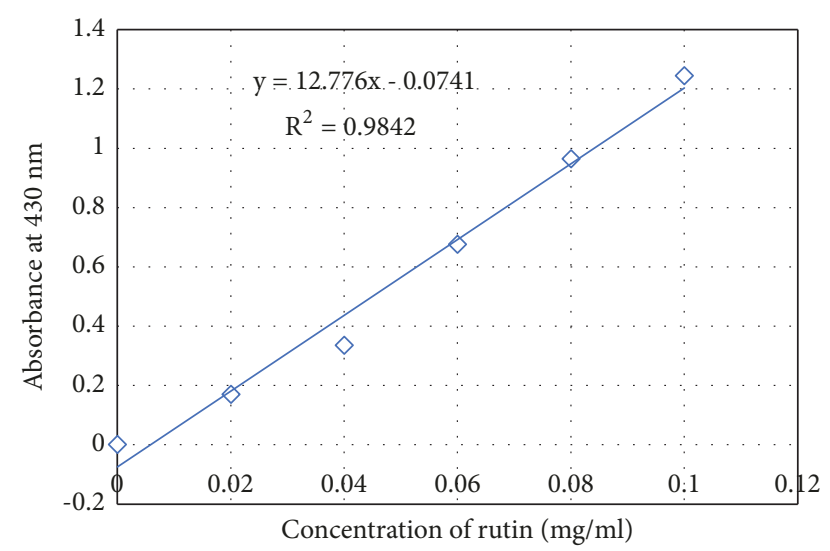

FIGURE 3: Calibration curve of rutin in determination of flavonoid content of C. edulis.

TABLE 2: $\mathrm{IC}_{50}$ values of $C$. edulis extracts and vitamin $\mathrm{C}$ in $\mathrm{DPPH}$ scavenging, ABTS activity, and reducing power assays.

\begin{tabular}{lcc}
\hline & \multicolumn{2}{c}{$\mathrm{IC}_{50}$ values } \\
Extracts & DPPH scavenging & Radical ABTS \\
\hline HEC & $0.321 \pm 0.019$ & $0.09 \pm 0.003$ \\
MEC & $0.310 \pm 0.027$ & $0.123 \pm 0.005$ \\
AEC & $0.304 \pm 0.013$ & $0.153 \pm 0.007$ \\
PC & $0.307 \pm 0.013$ & $0.135 \pm 0.006$ \\
Vit C & $0.313 \pm 0.005$ & $0.061 \pm 0.001$ \\
\hline
\end{tabular}

calibration curve of rutin (Figure 3). The hydroethanolic and methanolic extracts have a relatively significant content of $14.84 \pm 0.013 \mathrm{mg}$ and $12.02 \pm 0.017 \mathrm{mg}$, respectively, in contrast

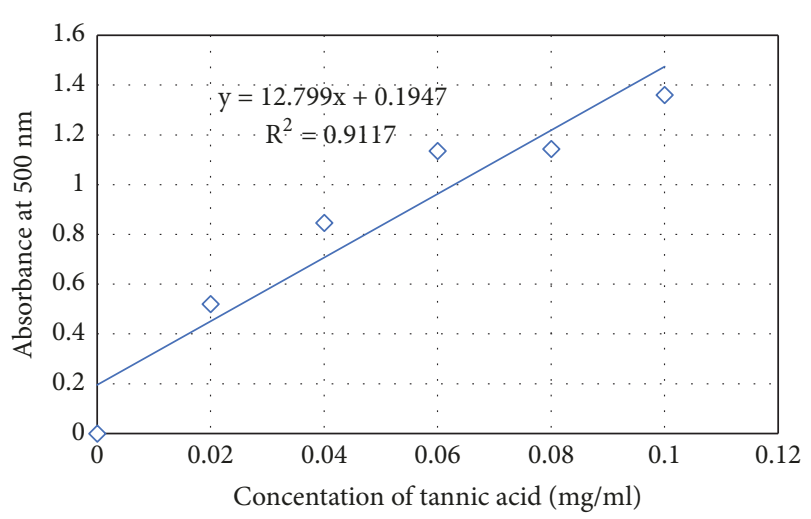

FIgURE 4: Calibration curve of tannic acid in determination of tannin present in C. edulis.

to aqueous extract and powder that had low content with 5.88 $\pm 0.120 \mathrm{mg}$ and $5.24 \pm 0.017 \mathrm{mg}$, respectively. The results are shown in Table 1.

3.5. Tannins Content. The tannin content of the leaves of C. edulis was determined according to the method using acidified vanillin. The results obtained from the standard curve of tannic acid (Figure 4) are expressed per mg of tannic acid per g of dry extract. Table 1 presents the results and it is found that the aqueous extracts have a low tannin content of $16.09 \pm 0.043 \mathrm{mg}$ compared to the other hydroethanolic, methanolic, and powder extracts with $26.76 \pm 0.048 \mathrm{mg}$, $34.67 \pm 0.042 \mathrm{mg}$, and $22.41 \pm 0.013 \mathrm{mg}$ tannin per gram of plant extract, respectively.

\subsection{Antioxidant Activity}

3.6.1. DPPH Radical Scavenging Activity. The DPPH test determines the ability of a compound or extract to trap a free radical. The results of the DPPH radical scavenging assay show that the various extracts of $C$. edulis possess radical scavenging power (Figure 5(a)) The inhibitory activity of the extracts increases in a dose-dependent manner with the concentration $(0.1-1 \mathrm{mg} / \mathrm{ml})$ of $58.63 \%$ to $94.67 \%$. All extracts at $0.1 \mathrm{mg} / \mathrm{ml}$ to $1 \mathrm{mg} / \mathrm{ml}$ showed a significant percentage inhibition compared to vitamin $\mathrm{C}$. The $\mathrm{IC}_{50}$ values are shown in Table 2. It defines the effective concentration of the extract that scavenges $50 \%$ of the DPPH radical ${ }^{-}$.

3.6.2. Reduction of Radical $A B T S^{+}$. It is one of the most used tests for determining the antioxidant activity of plant extracts. The results obtained presented in Figure 5(b) show that the percentage of inhibition of the various extracts increases 


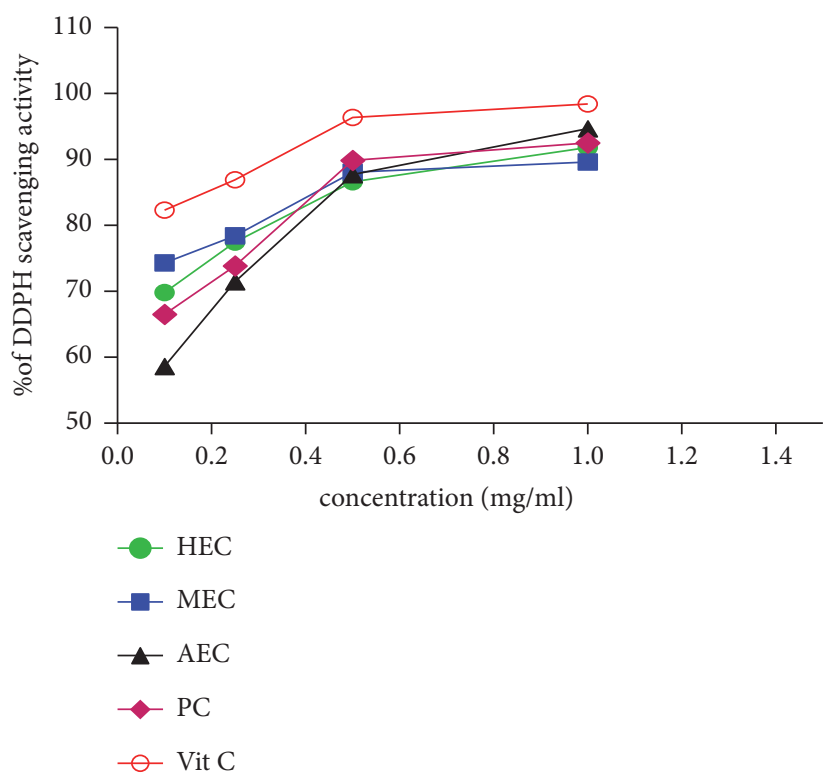

(a)

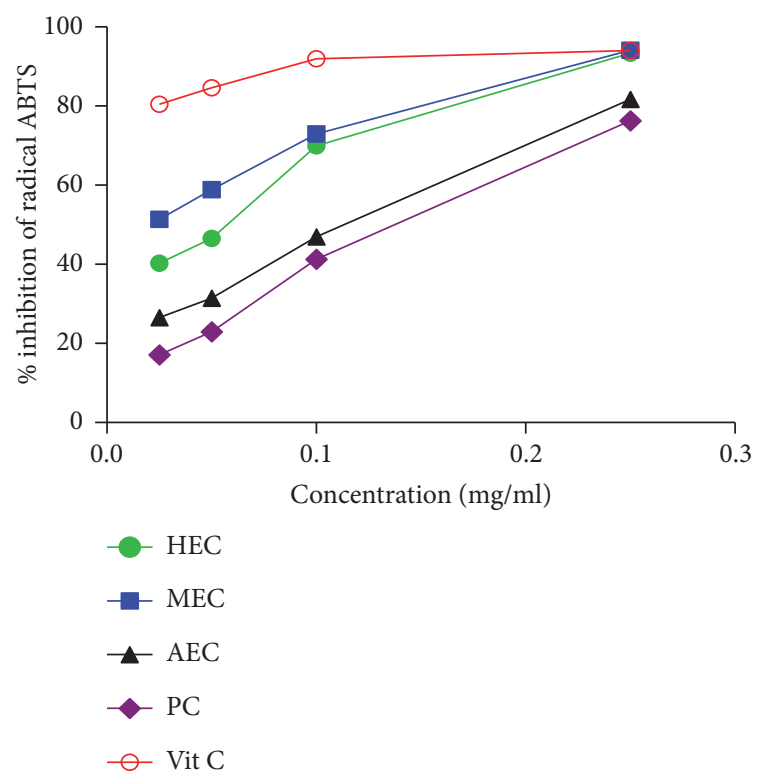

(b)

FIGURE 5: (a) DPPH radical scavenging activity of C. edulis. (b) Percentage inhibition of radical ABTS. HEC: hydroethanolic extract Carissa; MEC: methanolic extract Carissa; AEC: aqueous extract Carissa; PC: powder Carissa; Vit C: vitamin C.

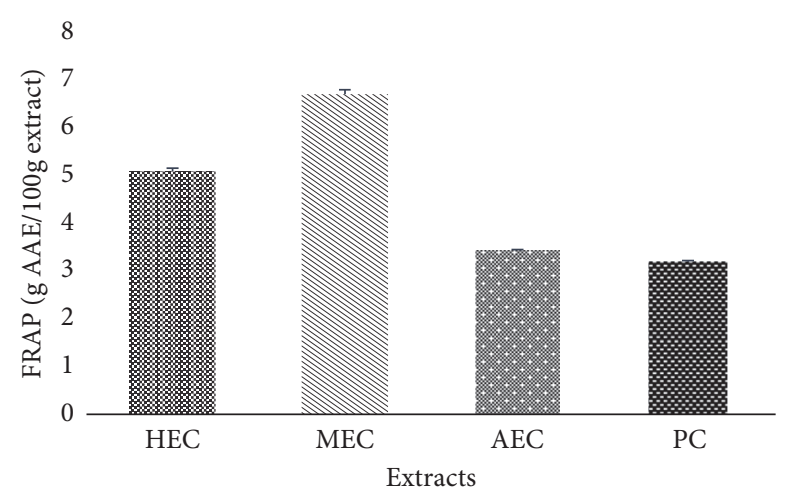

FIgure 6: Reducing power of extracts of C. edulis. HEC: hydroethanolic extract Carissa; MEC: methanolic extract Carissa; AEC: aqueous extract Carissa; PC: powder Carissa; Vit C: vitamin C. $\mathrm{n}=3$.

significantly in a dose-dependent manner. Aqueous extract and raw powder of $C$. edulis have relatively lower effect on ABTS inhibition activity ( $26.25 \%$ and $17.16 \%$, respectively) compared to the ascorbic acid which presented $80.41 \%$ at the lowest concentration of $0.025 \mathrm{mg} / \mathrm{ml}$. The $\mathrm{IC}_{50}$ value of the hydroethanolic extract is significantly comparable to the $\mathrm{IC}_{50}$ of the ascorbic acid standard. All data are represented in Table 2 .

3.6.3. Ferric Reducing Antioxidant Power. The iron reducing power test based on the reduction of $\mathrm{Fe}^{3+}$ iron to $\mathrm{Fe}^{2+}$ iron was used in this study to highlight the antioxidant potential of $C$. edulis. The results were calculated from the calibration curve of ascorbic acid and expressed in $\mathrm{g}$ of ascorbic acid per $100 \mathrm{~g}$ of extracts and presented in Figure 6. This shows that the methanolic extract has a high reducing capacity in the order of $6.73 \pm 0.09 \mathrm{~g} \mathrm{AAE} / 100 \mathrm{~g}$ followed by the hydroethanolic extract which is $5.17 \pm 0.03 \mathrm{~g} \mathrm{AAE} / 100 \mathrm{~g}$.

\section{Discussion}

Plants prove to be an important source of natural antioxidant that fight oxidative stress caused by an increase in free radicals/ROS such as superoxide $\mathrm{O}^{2-}$ anion, hydroxyl radical $\mathrm{HO}^{-}$, and also peroxide. The medicinal plants used in traditional medicine are particularly interesting for the study of their antioxidant activity. A study has already been done on the antioxidant capacity of the roots of C. edulis [19] and fruits [28].

In the present investigation, different extracts of C. edulis leaves were evaluated for phenolic compounds and antioxidant capacity. The variations in the antioxidant properties observed may be due to the polarity of the extraction solvents. These results indicated that, because of the diversity of chemical components, their availability for extractable solvents is the basic factor that can influence extraction efficiency $[29,30]$. It has also been suggested that the maceration method may be a better choice for the extraction of secondary metabolites.

In most medicinal plants, phenolic compounds such as flavonoids, tannins, and phenols are major contributors to antioxidant activity [31]. These are secondary metabolites found in plants and have a wide range of therapeutic effects. These phenolic antioxidants are potential radical scavengers and the potential to trap free radicals can be explained 
by hydroxyl phenolic groups $[19,32]$. A large amount of total phenolic content, flavonoids, and tannins are found in the leaves of C. edulis. A root tea study of C. edulis also revealed that this plant contains a high level of phenolic compounds $[18,33]$. These results are consistent with the works of Fowsiya and Madhumitha [28], which show that ethanolic and aqueous extracts also have a high content of total polyphenols and flavonoids. These phenolic compounds may be responsible for the antioxidant capacity of C. edulis.

The determination of the DPPH antioxidant activity of the extracts and the ascorbic acid standard was evaluated using the spectrophotometer by following the reduction and kinetics of decolorization of the DPPH radical. The percentage of inhibition and the $\mathrm{IC}_{50}$ of HEC, MEC, AEC, and PC extracts compared to ascorbic acid show that $C$. edulis has a high antioxidant capacity and that these extracts have the capacity to trap the DPPH radical as the reference antioxidant ascorbic acid. A previous study on the roots showed a percentage inhibition of DPPH of 62.7\% [34] and another on fruits a percentage of $80.48 \%$ [28]. Antioxidant molecules such as ascorbic acid, tocopherol, flavonoids, and tannins have been shown to induce DPPH decolorization due to their ability to donate hydrogen [35]. This implies that extracts of $C$. edulis can be used for the treatment of pathologies related to oxidative stress.

The antioxidant activity of the extracts was also evaluated by their ability to inhibit the $\mathrm{ABTS}^{*+}$ radical obtained from ABTS. This activity increases in a dose-dependent manner with the concentrations of the different extracts. The $\mathrm{IC}_{50}$ value of the methanol extract is close to that of the standard. The lower the $\mathrm{IC}_{50}$ value, the stronger the antioxidant power.

The total reducing power is another indicator test of the antioxidant activity of natural products. This antioxidant capacity of the extracts could result from the reduction of $\mathrm{Fe}^{3+}$ iron to $\mathrm{Fe}^{2+}$ based on electron gain which is an important mechanism of action of phenolic antioxidants [1]. The reducing power of the extracts decreases from MEC, HEC, AEC, and PC. The results of Woode [19] show that the hydroethanolic extract of the roots of $C$. edulis has a strong antioxidant power in reducing iron (III) similar to our results as HEC leaves have significant activity. Similarly, the ethanolic and aqueous extracts of the fruits showed a good reducing power [28]. In the FRAP test, the fact that $\mathrm{Fe}^{3+}$ accept an electron to become $\mathrm{Fe}^{2+}$ is responsible for the resulting green colour. The higher intensity of the colour shows that the extract has a significant reducing power. It is suggested that there is a direct correlation between antioxidant activity and reducing power of the components of some plants [36]. It is noted in this work that the results obtained show that the methanolic and hydroethanolic extracts of C. edulis have this ability to donate an electron to become more stable and thus act as antioxidant substances. Suitable solvents often used for the extraction of phenolic compounds from plant materials include alcohols (methanol and ethanol), acetone, and ethyl acetate [37].

HPLC can be used to separate, quantify, and identify polyphenols [38]. The HPLC chromatograms of the extracts have shown various peaks of compounds. All these compounds contained in the extracts of $C$. edulis may account for its antioxidant capacity. The most important compounds identified in our study are gallic acid, quercetin, and rutin. These were obtained by comparing their retention time with those of standard and the spectral characteristic of the peaks. The gallic acid was higher in the aqueous extract than the others with a percentage of composition of $22.63 \%$. Quercetin was found more in raw powder and methanolic extract. Gallic acid, quercetin, and rutin are phenolic compounds; this can justify the antioxidant activity of C. edulis.

\section{Conclusion}

The determination of the antioxidant activity and the quantification of the bioactive compounds of extracts obtained from Carissa edulis were evaluated. This work revealed to us that the different extracts of Carissa edulis, namely, the hydroethanolic, methanolic, and aqueous extracts, and the powder contain a high content of polyphenols, flavonoids, and tannins. Phenolic compounds such as gallic acid, quercetin, and rutin were identified and may be related to the antioxidant capacity of these plant extracts as measured by radical scavenging activity (DPPH and ABTS) ferric reducing antioxidant power.

\section{Data Availability}

All results presented in this study were carried out by authors and data used as references were properly cited.

\section{Conflicts of Interest}

There are no conflicts of interest.

\section{Acknowledgments}

We would like to thank TWAS for providing us with a fellowship that allowed us to carry out this work and also for Comsats Institute for Information Technology (CIIT) in Abbottabad, Pakistan, which hosted us for this fellowship. This work has been supported by The World Academy of Science and Comsats Institute of Information Technology [CIIT-TWAS PG Fellowship, 2016].

\section{References}

[1] L. Machu, L. Misurcova, J. V. Ambrozova et al., "Phenolic content and antioxidant capacity in algal food products," Molecules, vol. 20, no. 1, pp. 1118-1133, 2015.

[2] B. N. Ames, M. K. Shigenaga, and T. M. Hagen, "Oxidants, antioxidants, and the degenerative diseases of aging," Proceedings of the National Acadamy of Sciences of the United States of America, vol. 90, no. 17, pp. 7915-7922, 1993.

[3] A. M. O. Amoussa, A. Sanni, and L. Lagnika, "Antioxidant activity and total phenolic, flavonoid and flavonol contents of the bark extracts of Acacia ataxacantha," Journal of Pharmacognosy and Phytochemistry, vol. 4, no. 2, pp. 172-178, 2015.

[4] S. Saha, J. A. Shilpi, H. Mondal et al., "Ethnomedicinal, phytochemical, and pharmacological profile of the genus Dalbergia L. (Fabaceae)," Phytopharmacol, vol. 4, no. 2, pp. 291-346, 2013. 
[5] H. M. Al-Youssef and W. H. B. Hassan, "Phytochemical and pharmacological aspects of Carissa edulis vahl: a review," International Journal of Current Research in Chemistry and Pharmaceutical Sciences, vol. 1, no. 9, pp. 12-24, 2014.

[6] M. Giday, "An ethnobotanical study of medicinal plants used by the Zay people in Ethiopia," CBM: s Skriftserie, vol. 3, pp. 81-99, 2001.

[7] T. Nedi, N. Mekonnen, and K. Urga, "Diuretic effect of the crude extract of Carissa edulis in rats," Journal of Ethnopharmacology, vol. 95, no. 1, pp. 57-61, 2004.

[8] G. Addis, D. Abebe, and K. Urga, "A survey of traditional medicinal plants in Shirka district, Arsi Zone, Ethiopia," Ethiopian Pharmaceutical Journal, vol. 19, pp. 30-47, 2001.

[9] H. Ibrahim, E. M. Abdulrahman, M. Shok, N. Ilyas, K. Y. Musa, and I. Ukandu, "Comparative analgesic activity of the root bark, stem bark, leaves, fruits and seeds of Carissa edulis VAHL (Apocynaceae)," African Journal of Biotechnology, vol. 6, no. 10, pp. 1233-1235, 2007.

[10] H. Ibrahim, Pharmacognostic and Biological (Analgesic Activity) Studies of Carissa edulisVahl [Ph.D. thesis], Ahmadu Bello University, Zaria, Nigeria, 1997.

[11] R. Wangteeraprasert and Y. K. Likhitwita, "Lignans and a sesquiterpene glucoside from Carissa carandas stem," Helvetica Chimica Acta, vol. 92, pp. 1217-1223, 2009.

[12] R. Pal, D. Kulshreshtha, and R. P. Rastoqi, "A new lignan from Carissa carandas," Phytochemistry, vol. 14, pp. 2302-2303, 1975.

[13] M. D. Bentley, S. R. Brackett, and A. Chapya, "2-hydroxyacetophenone: principal root volatile of the east african medicinal plant, Carissa Edulis," Journal of Natural Products, vol. 47, no. 6, pp. 1056-1057, 1984.

[14] M. Moudachirou, M. A. Ayédoun, J. D. Gbénou, F.-X. Garneau, H. Gagnon, and F.-I. Jean, "Essential oil of carissa edulis vahl. From Benin," Journal of Essential Oil Research, vol. 10, no. 2, pp. 195-196, 1998.

[15] H. Ibrahim, R. A. Oyi, J. O. Ehinmidu, K. Y. Musa, and N. T. Bright, "Antimicrobial activity of the water extracts of the leaves and fruits of Carissa edulis Vahl (Apocynaceae)," Journal of Medicinal Plants Research, vol. 4, no. 11, pp. 1028-1032, 2010.

[16] F. K. El-Fiky, M. A. Abou-Karam, and E. A. Afify, "Effect of Luffa aegyptiaca (seeds) and Carissa edulis (leaves) extracts on blood glucose level of normal and streptozotocin diabetic rats," Journal of Ethnopharmacology, vol. 50, no. 1, pp. 43-47, 1996.

[17] J. Ya'u, A. Yaro, M. Abubakar, J. Anuka, and I. Hussaini, "Anticonvulsant activity of Carissa edulis (Vahl) (Apocynaceae) root bark extract," Journal of Ethnopharmacology, vol. 120, no. 2, pp. 255-258, 2008.

[18] F. M. Tolo, G. M. Rukunga, F. W. Muli et al., "Anti-viral activity of the extracts of a Kenyan medicinal plant Carissa edulis against herpes simplex virus," Journal of Ethnopharmacology, vol. 104, no. 1-2, pp. 92-99, 2006.

[19] E. Woode, C. Ansah, G. K. Ainooson, W. M. Abotsi, A. Y. Mensah, and M. Duweijua, "Anti-inflammatory and antioxidant properties of the root extract of Carissa edulis (forsk.) vahl (Apocynaceae)," Journal of Science and Technology, vol. 27, no. 3, 2008.

[20] A. Koch, P. Tamez, J. Pezzuto, and D. Soejarto, "Evaluation of plants used for antimalarial treatment by the Maasai of Kenya," Journal of Ethnopharmacology, vol. 101, no. 1-3, pp. 95-99, 2005.

[21] P. G. Kirira, G. M. Rukunga, A. W. Wanyonyi et al., "Antiplasmodial activity and toxicity of extracts of plants used in traditional malaria therapy in Meru and Kilifi Districts of
Kenya," Journal of Ethnopharmacology, vol. 106, no. 3, pp. 403407, 2006.

[22] X. Gao, M. Ohlander, N. Jeppsson, L. Björk, and V. Trajkovski, "Changes in antioxidant effects and their relationship to phytonutrients in fruits of sea buckthorn (Hippophae rhamnoides L.) during maturation," Journal of Agricultural and Food Chemistry, vol. 48, no. 5, pp. 1485-1490, 2000.

[23] N. Mimica-Dukic, Investigation on secondary biomolecules in some Mentha species [Ph.D. thesis], University of Novi Sa, 1992.

[24] Z. Bainbridge, K. Tomlins, K. Wellings, and A. Westby, Methods for Assessing Quality Characteristics of Non-Grains Starch Staples (Part 3. Laboratory Methods), Natural Resources Institute, Chatham, UK, 1996.

[25] D. Zhang and Y. Hamauzu, "Phenolics. ascorbic acid. carotenoïds and antioxidant activity of broccoli and their changes during conventional and microwave cooking," Food Chemistry, vol. 88, no. 4, pp. 503-509, 2004.

[26] R. Re, N. Pellegrini, A. Proteggente, A. Pannala, M. Yang, and C. Rice-Evans, "Antioxidant activity applying an improved ABTS radical cation decolorization assay," Free Radical Biology \& Medicine, vol. 26, no. 9-10, pp. 1231-1237, 1999.

[27] M. Oyaizu, "Studies on products of browning reaction Antioxidative activities of products of browning reaction prepared from glucosamine," Japanese Journal of Nutrition, vol. 44, pp. 307-315, 1986.

[28] J. Fowsiya and G. Madhumitha, "Preliminary phytochemical analysis, Antioxidant and cytotoxicity test of Carissa edulis Vahl dried fruits," IOP Conference Series: Materials Science and Engineering, vol. 263, article 022018, 2017.

[29] N. Hassim, M. Markom, N. Anuar, and K. H. Dewi, "Antioxidant and antibacterial assays on polygonum minus extracts: different extraction methods," International Journal of Chemical Engineering, vol. 2015, Article ID 826709, 10 pages, 2015.

[30] Z. G. Kanwal, A. Hafeez, I. U. Haq et al., "Antioxidant, antimicrobial and antileishmanial study of different parts of Peganum harmala," International Journal of Biosciences, vol. 9, no. 1, pp. 45-58, 2016.

[31] J. Dai and R. J. Mumper, "Plant phenolics: extraction, analysis and their antioxidant and anticancer properties," Molecules, vol. 15, no. 10, pp. 7313-7352, 2010.

[32] T. Sawa, M. Nakao, T. Akaike, K. Ono, and H. Maeda, "Alkylperoxyl radical-scavenging of various flavonoids and other phenolic compounds: implications for the anti-tumor-promoter effect of vegetables," Journal of Agricultural and Food Chemistry, vol. 47, no. 2, pp. 397-402, 1999.

[33] E. A. Omino and J. O. Kokwaro, "Ethnobotany of Apocynaceae species in Kenya," Journal of Ethnopharmacology, vol. 40, pp. 167-180, 1993.

[34] L. Aksoy, E. Kolay, Y. Agilonu, Z. Aslan, and M. Kargioglu, "Free radical scavenging activity, total phenolic content, total antioxidant status and total oxidant status of Thermopsis turcica," Saudi Journal of Biological Sciences, pp. 20235-20239, 2013.

[35] H. L. De Pooter and et Schamp N., "Comparison of the volatils composition of some Calamintha satureja species," in Progress in Essential Oil Research, E.-J. Brunk, Ed., pp. 139-150, Walter De Gruyter, Berlin, Germany, 1986.

[36] S. Sahreen, M. R. Khan, and R. A. Khan, "Evaluation of antioxidant activities of various solvent extracts of Carissa opaca fruits," Food Chemistry, vol. 122, no. 4, pp. 1205-1211, 2010. 
[37] J. Reenu, S. Azeez, and C. Bhageerathy, "In vitro antioxidant potential in sequential extracts of Curcuma caesia Roxb," Indian Journal of Pharmaceutical Sciences, vol. 77, no. 1, pp. 41-48, 2015.

[38] S. A. A. D. Houda, Développement de bio composite à base de fibres végétales et colles écologique [Ph.D. thesis], Université de Pau et de l'Aldour, 2013. 


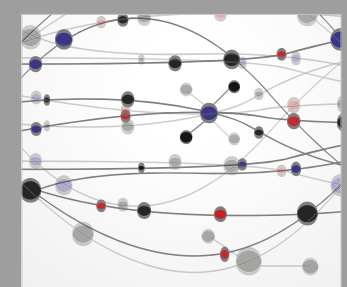

The Scientific World Journal
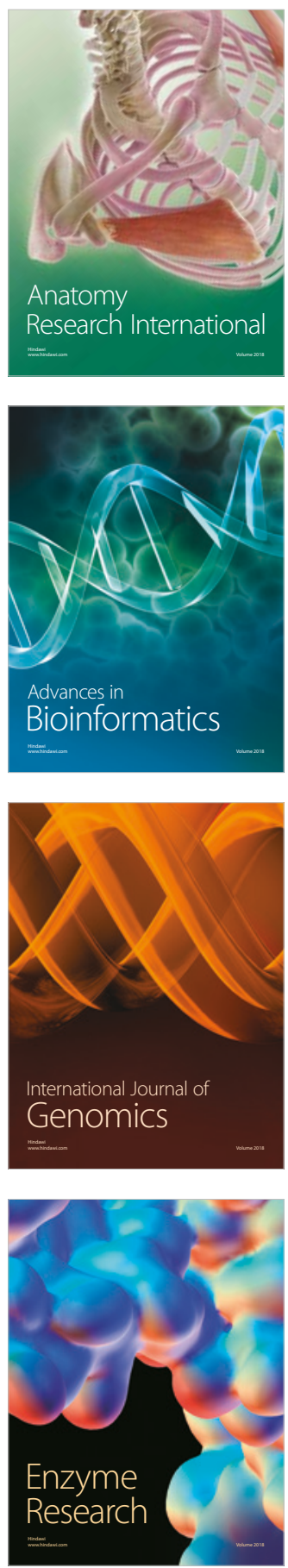
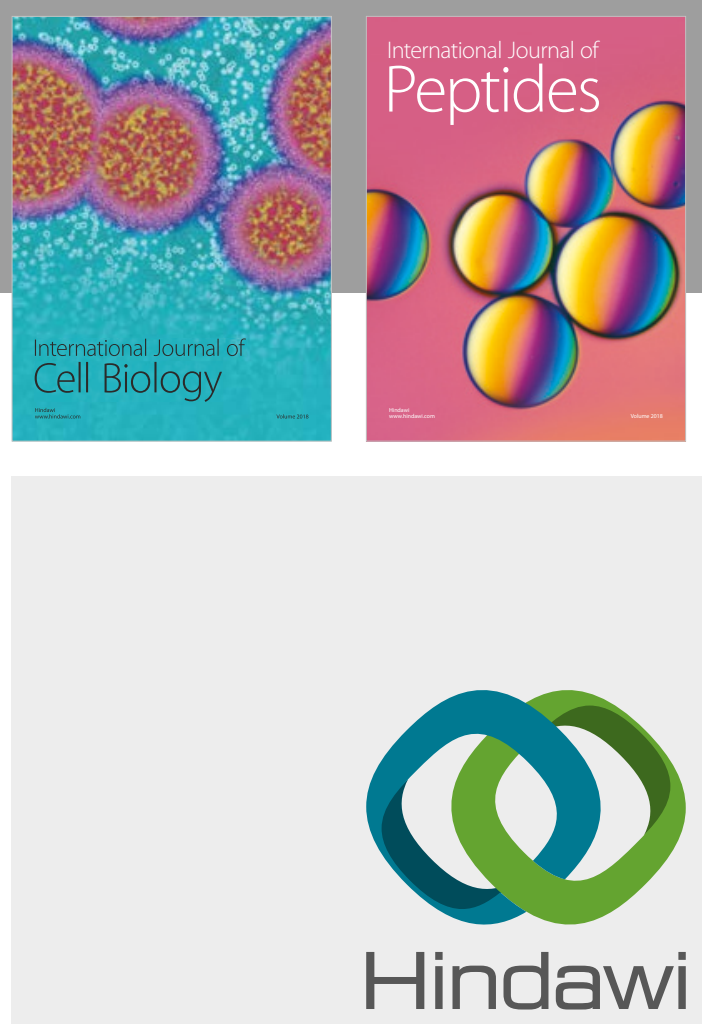

Submit your manuscripts at

www.hindawi.com
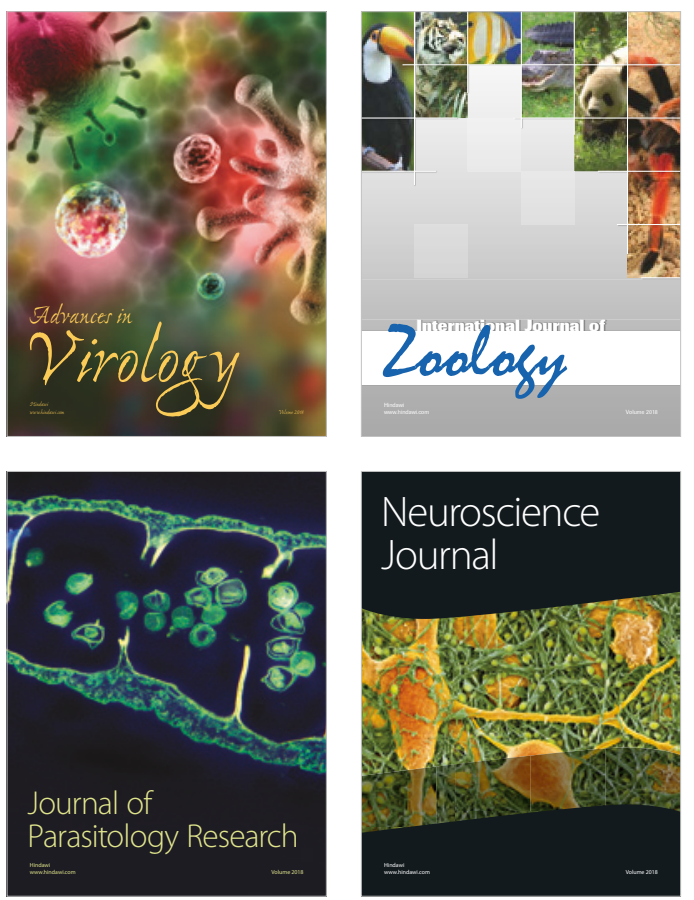
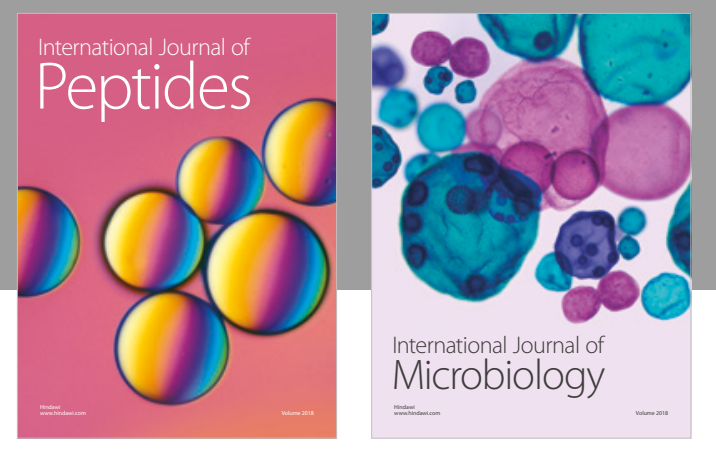

nternational Journal of Microbiology
Journal of
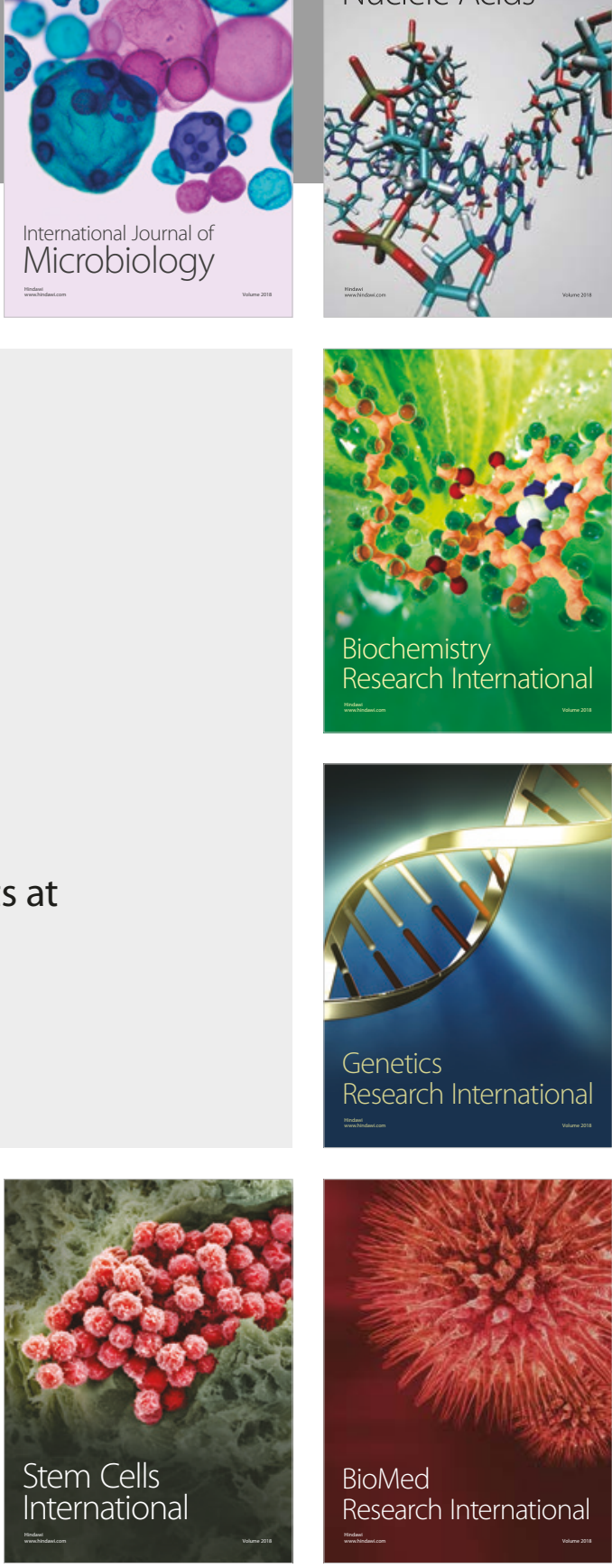
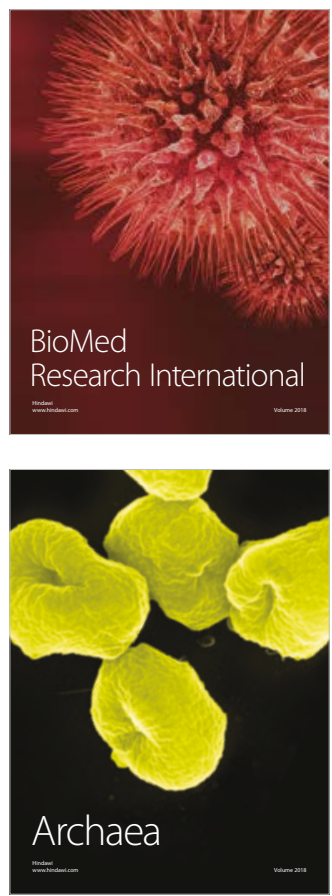